\title{
Adolescent Susceptibility to Deviant Peer Pressure: Does Gender Matter?
}

\author{
Shelly S. McCoy ${ }^{1}$ Laura M. Dimler ${ }^{2} \cdot$ Danielle V. Samuels $^{2} \cdot$ Misaki N. Natsuaki ${ }^{2}$
}

Received: 8 August 2017 / Accepted: 16 September 2017 / Published online: 25 September 2017

(C) The Author(s) 2017. This article is an open access publication

\begin{abstract}
It is well known that adolescent risk-taking behaviors often occur in social settings among peers, however, it is unclear whether there are gender differences in the susceptibility to deviant peers, an antecedent to risk-taking behaviors. This qualitative review examines gender differences in adolescent susceptibility to deviant peer pressure in order to better understand processes that contribute to adolescent risk-taking behavior. The review of 26 studies revealed two primary trends: (1) compared to adolescent females, adolescent males appear to be more susceptible to peer influences that encourage risk-taking behaviors, or (2) there is no consistent gender difference in susceptibility to such peer influences. Only two studies reviewed suggested adolescent females to be more susceptible to deviant peer pressure than adolescent males. The discussion offers two useful perspectives that may explain the two trends in the literature. First, gender role socialization theory is consistent with the observed trend that adolescent males are more susceptible to deviant peer pressure for risk-taking behaviors than females as they seek alignment with the masculine ideal. Second, the conceptual and methodological issues, such as using typically male-dominated risk-taking tasks and assessments (i.e., delinquency scale) to measure both males' and females' outcomes, may obscure underlying patterns of gender differences in susceptibility to peer influence. Future researchers are encouraged to empirically examine these trends in order to create appropriate interventions.
\end{abstract}

Shelly S. McCoy

smccoy@lasierra.edu

1 Department of Psychology, La Sierra University, 4500 Riverwalk Pkwy., Riverside, CA 92505, USA

2 University of California, Riverside, 900 University Ave., Riverside, CA 92507, USA
Keywords Gender - Deviant peer pressure - Risky behavior $\cdot$ Adolescence $\cdot$ Review

\section{Introduction}

Risk-taking behaviors during adolescence contribute to high rates of unintentional injury (Sleet et al. 2010; Turner et al. 2004) and are a leading cause of death among adolescents in the United States (Heron 2016). A consistent finding in the developmental literature is the correlation between adolescent risk-taking behaviors (e.g., delinquency, substance use, risky sex) and those of their peers (Crosnoe and McNeely 2008; Flannery et al. 1994; Prinstein and Wang 2005). Developmentally, peer reference groups become increasingly salient during adolescence, and most risk-taking behaviors occur within the peer context (Crosnoe and McNeely 2008). Although some studies suggest that adolescent males engage in more of some types of risk-taking behaviors (i.e., substance use and delinquency; Erickson et al. 2000) and have more deviant peer affiliations than females (Mears et al. 1998; Svensson 2003), it remains unclear "whether the social processes [emphasis added] leading to these outcomes also differ by gender" (Erickson et al. 2000, p. 402).

This qualitative review attempts to answer the question of whether adolescent males or females are more susceptible to deviant peer pressure, and it posits hypotheses gleaned from the literature. Consistent with prior conceptualizations (i.e., Brown et al. 1986; Santor et al. 2000), this review considers deviant peer pressure to be a social factor that increases adolescents' tendency to engage in risk-taking behaviors, including substance use, promiscuous or unprotected sex, and delinquency, and focuses on their subjective experience and feeling of pressure from deviant peers to engage in risk-taking behaviors (as opposed to the presence of deviant 
peers in their social network). Whereas gender differences in risk-taking behavior have been the subject of much research (e.g., Byrnes et al. 1999), questions about gender differences in the social processes preceding risk-taking behaviors has received less attention. The purpose of this review is to utilize an interdisciplinary approach to fill this gap in the literature by examining the role of gender in adolescents' subjective experience of deviant peer pressure.

\section{Adolescence: A Time for Gender Salience and Peer Influences}

From a developmental perspective, gender roles, norms, and expectations become especially salient to youth during early and middle adolescence (Hill and Lynch 1983), and this notion is supported by evidence from longitudinal studies (e.g., Galambos et al. 1990). This occurs, in part, as a function of gender socialization processes in which socializing agents, such as parents, peers and the media, shape gender norms and behavioral expectations. These agents are powerfully influential throughout development, but they are particularly so earlier in childhood (Leaper and Friedman 2007) and again during pubertal development (Hill and Lynch 1983). It is hypothesized that one such reason for this increase in gender-role attitudes is that it stems from the elevated importance of peers during adolescence (Perry and Pauletti 2011).

As such, adolescence is not just a time for the increasing importance of peer relationships, but it is also a time of increased susceptibility to peer pressure. It is clear from previous studies that peers affect adolescents' decisions to engage (or not engage) in risky behaviors (Blakemore and Mills 2014; Miller 2009). Social acceptance becomes central to much of adolescent behavior, perhaps because it is a developmentally sensitive period in which youth are highly attuned to picking up on and responding to social cues from their social environments (Blakemore and Mills 2014). Thus, to the degree that social conformity is perceived as central to popularity among peers, early and middle adolescents are especially vulnerable to peer pressure as they strive toward peer approval and acceptance (Gavin and Furman 1989).

\section{Who are More Resistant to Deviant Peer Pressure: Males or Females?}

Evidence on gender differences in risk-taking behavior is mixed. Some studies find that these differences may change over historical time or development, and can differ across types of risk-taking behaviors. For example, although meta-analytic findings have shown that males are more prone to risk-taking (or more likely to engage in risk-taking behaviors), the size and significance of the effects vary across domains and by age (Byrnes et al. 1999; Storvoll and Wichstom 2002), suggesting that other salient factors in adolescence may be at play (i.e., peer pressure). Additionally, the desirability of engaging in risk-taking behaviors and succumbing to peer pressure may differ for males and females (Byrnes et al. 1999; Closson 2009). Prior research has shown that adolescents who are more susceptible to peer pressure have more difficulty establishing social competence and have a harder time making their own judgments about risk-taking behaviors (Allen et al. 2006). Similarly, Young et al. (2009) qualitative study found that college females described their drinking patterns as motivated by pressure to make favorable impressions on their male peers. As such, it is important to identify factors that contribute to certain youth's heightened vulnerability to peer pressure. For example, adolescent females are often thought of as being more resistant to deviant peer influences than males (Hanish et al. 2005). However, gender differences in susceptibility to deviant peer pressure have not been thoroughly examined in the literature. As discussed below, there are three mutually exclusive hypotheses regarding gender and susceptibility to peer pressure in adolescence.

One hypothesis suggests that females are more resistant to deviant pressure than are males. This idea is supported by research showing that adolescent females' sensitivity to social relationships is an asset facilitative of interpersonal competence rather than deviance (Rose and Rudolph 2006). In this way, females may be better able to resist deviant peer influences as they simultaneously consider how their involvement in risky behaviors might damage other highly valued (or prioritized) relationships with parents, teachers, and friends. Indeed, prior work has indicated that adolescent females are more skillful at balancing both affiliation and reputational needs (Sheldon 1992), whereas adolescent males may be more likely to prioritize status goals (LaFontana and Cillessen 2010) and may be more focused on dominance hierarchies (Rose and Rudolph 2006).

An alternative hypothesis is that females may be less resistant to deviant peer pressure than males. It has been established that adolescent females tend to have heightened sensitivity to social-evaluative concerns, or a reliance on close relationships as a source of self-evaluation and selfworth (Rudolph and Conley 2005), and are more attuned to the benefits of peer conformity for the aims of acceptance, popularity, and likability. While females' heightened attunement to social-evaluative cues and need for approval are generally thought of as beneficial to their interpersonal relationships (i.e., Rose and Rudolph 2006), this sensitivity may be detrimental if it is manifested as a heightened sensitivity to peer pressure as a means of preserving close relationships. Indeed, in a study of young children, in comparison with males, females were more negatively influenced (i.e., 
evidenced increased aggression) by exposure to externalizing peers. Interestingly, the non-gender-normative nature of those behaviors made them particularly powerful, such that when females are exposed to gender-atypical behaviors (e.g., aggression, rule-breaking), their influences are especially salient (Hanish et al. 2005).

A third explanation is that adolescent males and females may experience similar peer pressure across domains, but the adolescent, regardless of gender, who has a stronger peer orientation may be the influencing factor in who is less resistant to deviant peer pressure, hence explaining why some studies find no gender difference (Abbott-Chapman et al. 2007; Blais and Weber 2001; Brown 1982). In their study of early adolescents' susceptibility to peer influence, Allen and colleagues found no evidence of a moderating effect of gender, indicating that both males and females who scored higher on a generalized measure of susceptibility to peer influence were both at greater risk of early sexual behavior, externalizing behaviors and substance use (Allen et al. 2006). Similarly, Miller (2009) found that, for both adolescent males and females, susceptibility to peer influence is a risk factor for delinquency. Further, longitudinal findings have shown that adolescents with an extreme peer orientation [i.e., a "negative aspect of peer orientation (in which adolescents) would sacrifice developmentally positive aspects of their lives to maintain these relationships", p. 625] are involved in increased problem behaviors three years later, regardless of gender, as they abandon parental influences in favor of peer influences (Fuligini et al. 2001). These studies support the hypothesis that susceptibility to deviant peers is predictive of risk-taking behaviors yet suggest that several types of associations between gender and deviant peer pressure are possible.

It is important to note that all three of these explanations are equally plausible and that the current literature does not lend a clear interpretation regarding which hypothesis is empirically supported. Therefore, the present study aims to systematically sift through the current literature and conduct a qualitative review.

\section{The Present Study}

Previous research clarifies the role of peer influence as central to adolescent risk-taking. Together with research on gender role socialization processes and the gender intensification hypothesis, prior studies provide a foundation from which to conduct a more thorough examination of the relationship between gender and susceptibility to deviant peer influences. A growing body of work has begun to establish the predictive power of susceptibility to deviant peer influence on adolescents' risk-taking behaviors, a determinant of behavior that appears to be a general risk factor across genders. Building on the burgeoning research showing adolescents are highly attuned to picking up on and responding to social cues from their environments (Blakemore and Mills 2014), we examine whether and how deviant peer influence affects adolescent males and females differently during a period of development in which gender stereotypes may be especially influential in shaping perceived social norms (de Visser and McDonnell 2011; Young et al. 2009).

An additional aim is to propose theoretical explanations for the observed findings. To achieve this, we first organize the existing literature on gender differences in susceptibility to deviant peer influence after a careful survey of the literature for studies that met the inclusionary criteria. As previously described, we begin by identifying studies that have examined gender differences, not in risk-taking itself, but in susceptibility to deviant peer influence, an antecedent to risk-taking behaviors. Second, based on a review of the literature, we introduce hypotheses, described below, to explain the observed trends and stimulate future research.

\section{Methods}

Studies for this qualitative review were chosen based on several criteria. Our independent variable was gender and the dependent variable was susceptibility to deviant peer pressure. Consistent with others in the field, we operationalized peer pressure as the subjective experience of social influence (Brown et al. 1986; Santor et al. 2000) to engage in risk-taking behaviors. Because our primary interest was to understand adolescents' subjective experience of deviant peer influence, we focus mostly on adolescents' self-reported experiences of peer influence, but also included a few experimental studies of deviant peer influence that reported findings separately for males and females. These experimental studies' results were based on adolescents' behavior in the presence and absence of a deviant confederate.

Due to the dearth of studies that have directly examined the question of whether adolescent males or females are differentially susceptible to deviant peer pressure using a subjective scale, our operational definition of susceptibility to deviant peer pressure includes a broad spectrum of measures assessing both pressure to engage in specific risk-taking behaviors, such as delinquent activities (Crockett et al. 2006), as well as measures that assess the broader experience of peer pressure without reference to specific behaviors (i.e., asking participants to respond to conflicting hypothetical situations such as, "Some people go along with their friends just to keep their friends happy" and "Other people refuse to go along with what their friends want to do, even though they know it will make their friends unhappy"; Steinberg and Monahan 2007). As stated in the reviewed literature, peer influence on risk-taking behaviors tends 
to peak from early adolescence (LaFontana and Cillessen 2010) to emerging adulthood (Bradley and Wildman 2002); therefore, we included studies that assessed peer pressure in early, middle, and late adolescence, as well as studies with college students.

The following criteria were used in the literature search. The studies must have been available in peer-reviewed English language journals. These studies were obtained through (a) searching online and computerized data bases (e.g., PsycINFO) using all combinations of the keywords: adolescent, peer pressure, peer influence, gender, susceptibility to peer influence, and resistance to peer influence and (b) examining references cited in prior reviews and empirical studies. We did not restrict our review to studies published within a specified time period.

Several types of peer studies, while relevant from a broader perspective on peer relations and risk-taking, were excluded. First and importantly, we excluded studies that assessed associations between deviant peer affiliations and risk-taking behavior but that did not include a separate measure assessing adolescents' experience of peer pressure or peer influence. Second, studies that have examined deviant peer affiliations (Prinstein et al. 2001), peer contagion (Cohen and Prinstein 2006), and deviancy training (e.g., Dishion et al. 1996; Svensson 2003) using sociometric nominations without measuring the direct, subjective experience of peer pressure (e.g., Prinstein and Wang 2005) were excluded. These types of studies helped to clarify that peer behavior is correlated with adolescents' risk behavior involvement, but do not directly address whether males and females experience peer pressure differently. Finally, studies that do not test gender effects (e.g., Storvoll and Wichstrom 2002) were excluded. Even when studies collected gender information, we could not include some studies in our review because they did not formally test gender effects in final analyses when gender did not statistically contribute to the prediction of risktaking in preliminary analysis (e.g., Trucco et al. 2010; Urberg 1992). We outlined the details of the process of inclusion and exclusion in a PRIMSA figure (Moher et al. 2009). We eventually identified 26 studies that met the outlined criteria (see Fig. 1).
Fig. 1 PRISMA flowchart of search and selection strategy

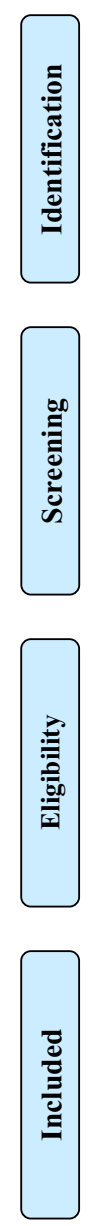

Records identified through database
searching $(\mathrm{n}=706)$
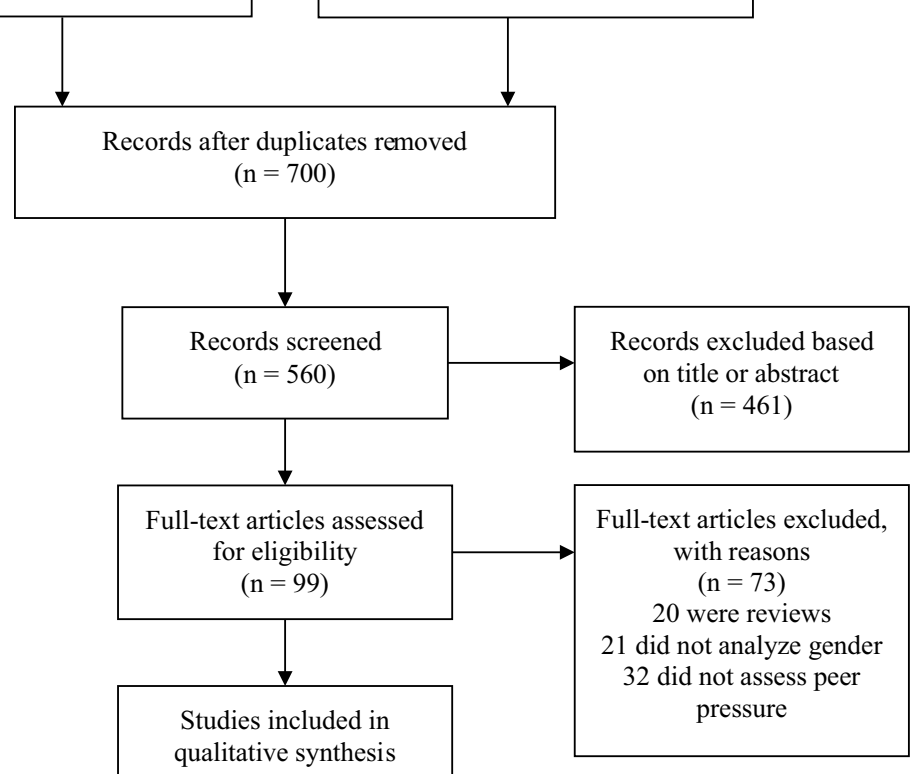

Additional records identified through other sources $(\mathrm{n}=110)$
Studies included in $(\mathrm{n}=26)$ 


\section{Results}

A summary of the 26 studies reviewed appears in Table 1 . We found that there is no gold standard assessment within this literature for measuring susceptibility to peer pressure, as noted by the plethora of measures that aim to assess this variable. Some researchers have employed hypothetical vignettes or experimental paradigms with peer presence, whereas others used single-item measures, but most used self-reports of subjective perceptions of deviant peer pressure or peer pressure more broadly.

Despite this caveat, among these 26 studies, we identified that $46 \%$ of studies $(n=12)$ suggest males are more prone to experience deviant peer pressure than females, yet $46 \%$ of the studies $(n=12)$ also found no gender difference in susceptibility to deviant peer pressure. A small minority of studies ( $n=2$; Nahom et al. 2001; Shepherd et al. 2011) demonstrated a greater female proneness to be susceptible to peer pressure. Thus, our review of the literature does not appear to support the argument that adolescent females are more susceptible to deviant peer pressure.

\section{Discussion}

The aim of the present review was to organize the existing literature on gender differences in the susceptibility to deviant peer pressure. Previous studies have revealed two patterns between gender and susceptibility to peer pressure: (1) $46 \%$ of the reviewed studies showed more male sensitivity to peer pressure in the context of risk-taking; and (2) $46 \%$ showed no gender difference. There was a lack of strong evidence ( $8 \%$ of the reviewed studies) that females are more susceptible to peer pressure than males within the risk-taking domains included in the present review. These mixed results led us to consider several possible explanations. First, we discuss gender role socialization theory and focus on masculine ideals as explanations for why males may be more susceptible than females to deviant peer influence. Next, we explore possible reasons why several studies found no gender difference in adolescent susceptibility to deviant peer pressure. Finally, we identify broader theoretical and measurement issues in the study of susceptibility to peer pressure.

\section{Adolescent Males' Heightened Susceptibility to Deviant Peer Pressure}

Nearly half of the studies reviewed here indicated that adolescent males are more susceptible to deviant peer pressure than females. One explanation for this finding is that adolescent males may be more influenced by deviant peer pressure as they attempt to fit traditional images cast by gender role stereotypes that link masculinity with toughness and autonomy, as is the case for substance use and aggressive behavior (Courtenay 2000; Mahalik et al. 2007). In this way, gender role stereotypes, which intensify during adolescence (Hill and Lynch 1983), may not only be descriptive of gendered behavior, but prescriptive as well (Fiske and Stevens 1993). The increasing salience of gender role stereotypes during adolescent development juxtaposed against socialization pressures from peers can heighten adolescents' awareness about the consequences of deviating from masculine and feminine norms for males and females, respectively. For instance, studies have shown that early adolescents perceive social status and risky, defiant behaviors to be more closely associated with male popularity and peer approval (Closson 2009; Iwamoto and Smiler 2013; Mahalik et al. 2007; Rienzi et al. 1996; Schulte et al. 2009), and males who deviate from gender-congruent expectations experience negative social consequences, such as peer rejection (Bosson et al. 2006; Mora 2012). As a result, males may feel socialization pressures to assert traditionally masculine behaviors such as rule-breaking and defiance.

In addition to the aforementioned explanation that adolescent males are more susceptible to deviant pressure as a consequence of gender socialization processes or as a means for better aligning with the masculine ideal, there is evidence to suggest that adolescent males are more prone to risk-taking than females because their social environments afford them more opportunities, such as more access to delinquent peers (Mears et al. 1998) and less adult supervision (Boyer and Byrnes 2009). For example, Boyer and Byrnes (2009) assessed the frequency of different types of risk-taking opportunities, such as being at a party with alcohol, and found that adolescent males engaged in more risk-taking behaviors in part because they reported more situational opportunities for deviance than females. To the degree that males report having more deviant peers than females (Dishion et al. 1996; Mears et al. 1998), they may simply have more social opportunities to experience deviant peer influence, rather than being more susceptible to deviant peer influence than females.

The third perspective as to why adolescent males may be more susceptible to deviant peer pressure than females may be due to the types of behaviors in which males face more peer pressure to engage during adolescence. For example, adolescent males' risk-taking is known to be associated with a strong peer orientation (Michael and Ben-Zur 2007), but adolescent females' risk-taking behaviors have been correlated with peer and non-peer relationships such as parental relationship quality (i.e., emotional closeness, communication and mutuality). Thus, a peer-socialization model suggesting that peers are more salient relationships for male adolescents than female adolescents, who are focused on both peer and non-peer relationships, ought to be considered. 


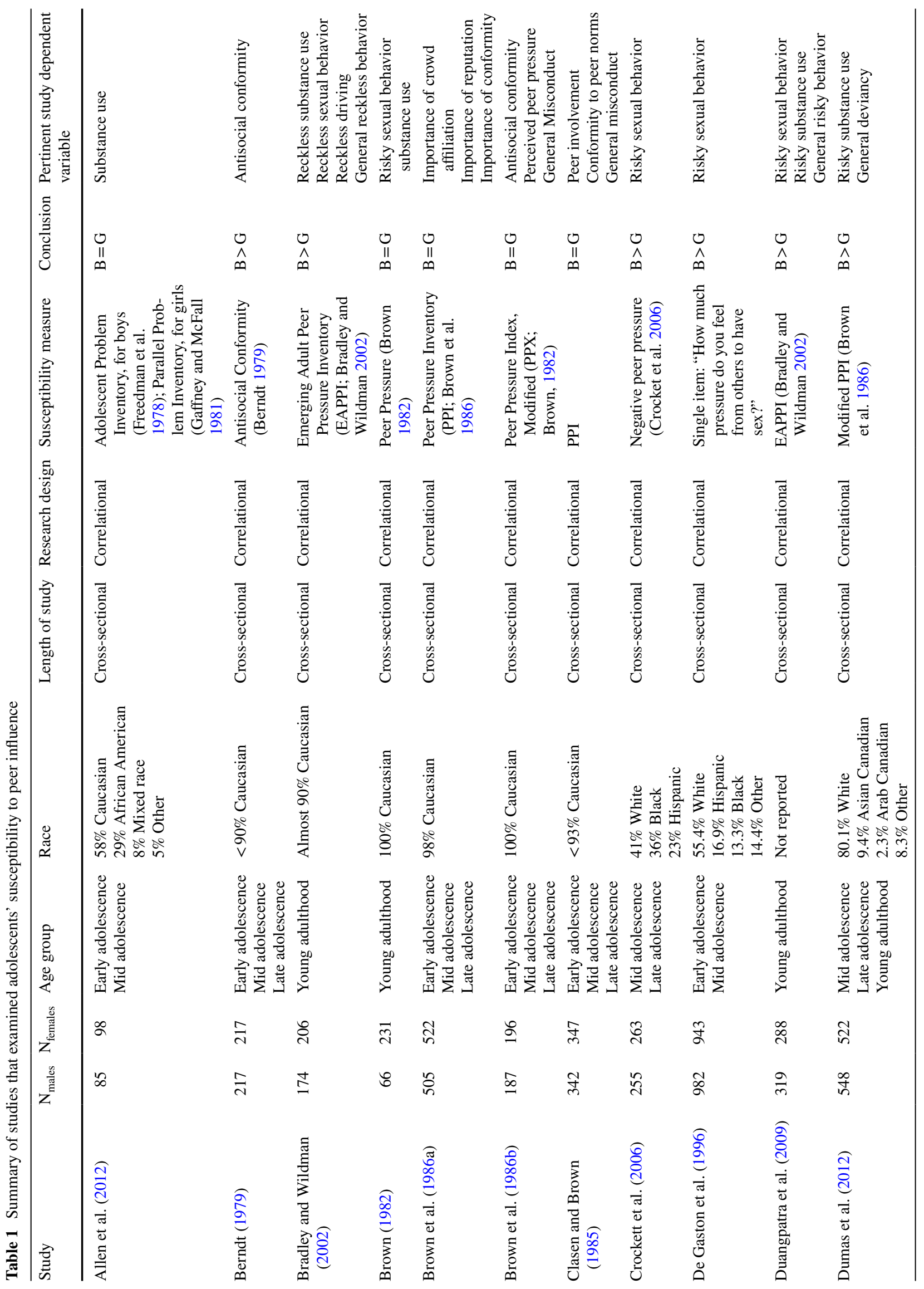




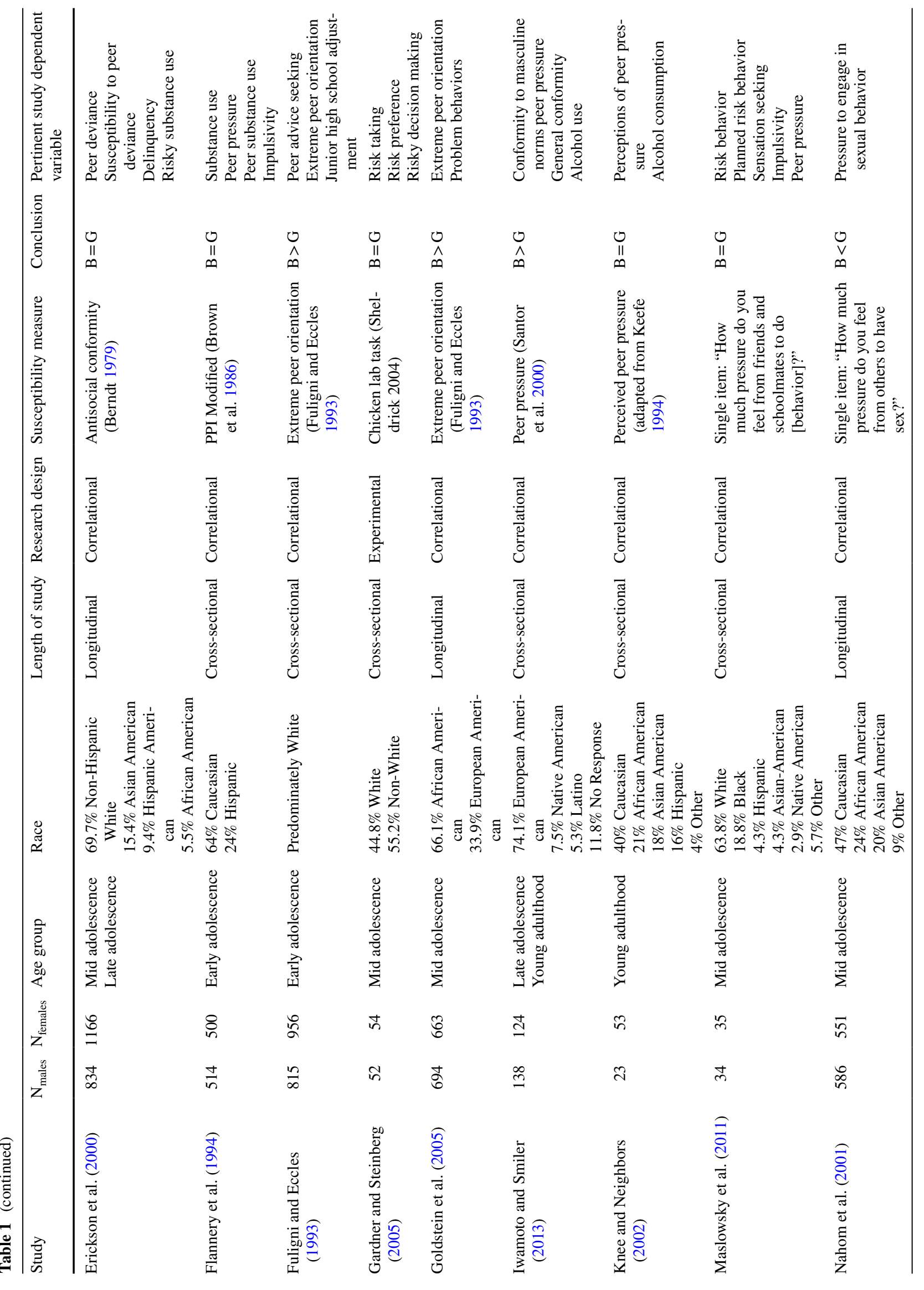




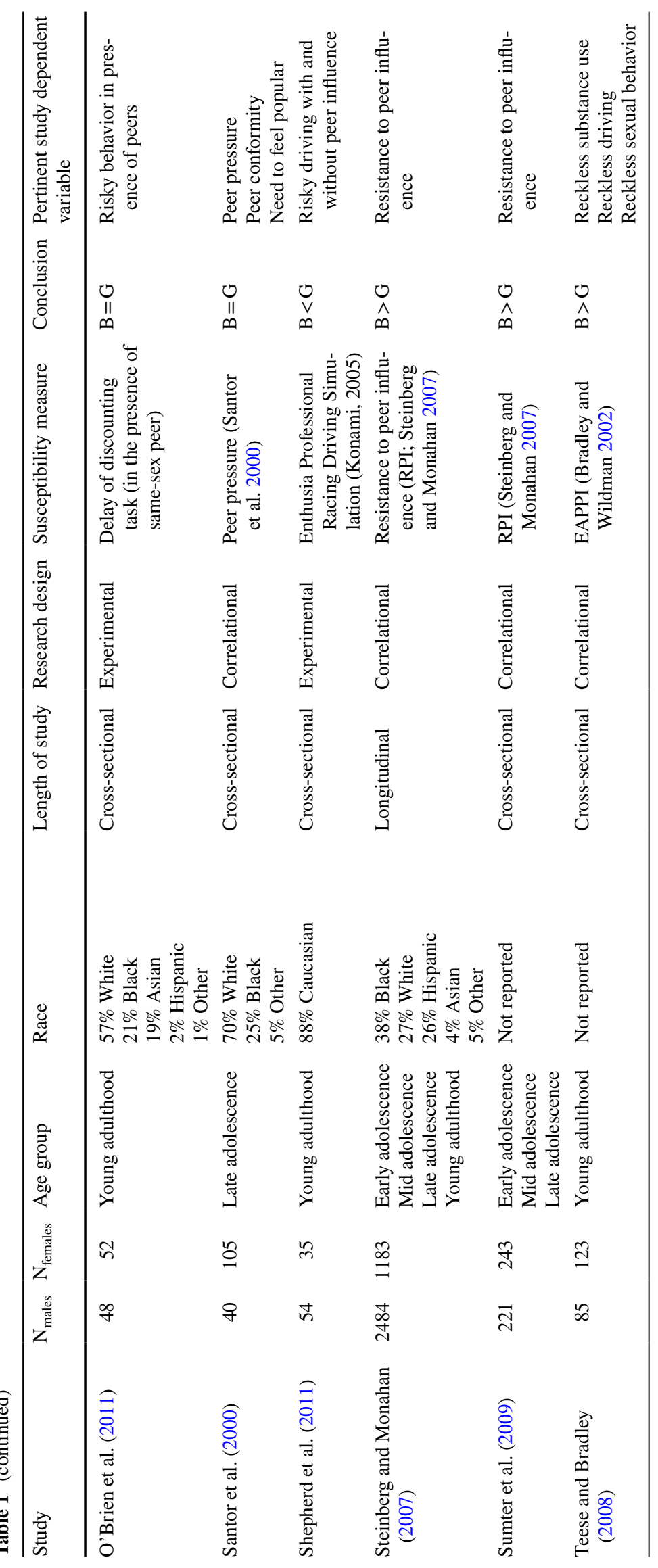


Additionally, this hypothesis may explain why adolescent males are more susceptible to deviant peer pressure (Rose and Rudolph 2006).

The fourth possible explanation for adolescent males' susceptibility to deviant peer pressure is that adolescent males may be less cognitively and emotionally equipped than females with coping skills and regulatory capabilities that help them effectively resist deviant peers (Steinberg and Monahan 2007). For example, one study found that midadolescent males are more likely to engage in (hypothetical) delinquent behavior regardless of perceived consequences than females, whereas females display more temperance and perspective, indicators of more advanced psychosocial maturity (Cauffman and Steinberg 2000). Relative to adolescent males, adolescent females' social competence (Allen et al. 2006; Rose and Rudolph 2006) and socialization differences in their moral development (Gilligan 1982; Mears et al. 1998) may also provide a greater buffer against deviant peer influences. For example, although youth's moral considerations (i.e., evaluating how right or wrong deviant behaviors are) of delinquent behaviors reduces susceptibility to deviant peers for both adolescent males and females, males are still more susceptible to deviant peers even if their own disapproval of delinquent behavior is strong (Mears et al. 1998). On the other hand, if females strongly disapprove of delinquent behaviors, the effect of delinquent peers is not significantly different than zero. This finding led Mears and colleagues to conclude that gender differences in delinquency stem from differences in psychosocial skills and regulatory abilities that influence moral decision-making.

\section{No Gender Differences in Susceptibility to Peer Pressure}

While nearly half of the reviewed articles showed male susceptibility to deviant peer pressure, the other half of studies reviewed showed non-significant gender differences. There are two possible interpretations for these patterns of results. One explanation is that, given evidence that males and females engage in similar mean levels of risk-taking behavior (e.g., Abott-Chapman et al. 2007; Santor et al. 2000), it is possible that they have similar susceptibility to deviant pressure to engage in such behavior as well. As attitudes about gender appropriate behavior shift across historical time, it may also be the case that adolescent male and female experiences are becoming increasingly similar, at least in some ways. For example, adolescent males and females may experience comparable levels of deviant peer pressure around substance use in particular (Santor et al. 2000).

A second possibility is that gender differences may exist, but are masked by the methodological issues in the present study. For instance, domains of risky behaviors may moderate the gender effect on peer susceptibility. Specifically, males and females may experience peer pressure for different types of risky behaviors (Brown 1982; Brown et al. 1986b), but when all the types are combined, as was done for most articles included in this review, overall gender differences may disappear. Whereas males may be more susceptible to deviant peer influences to engage in risky behaviors that are overt and antisocial (Berndt 1979; Brown et al. 1986a), females may be more vulnerable to other deviant social pressures to engage in less overt behaviors not captured in the measures used by the studies reviewed. For instance, evidence shows that, compared to male counterparts, adolescent females feel more pressure from friends and the media to lose weight and pursue thin ideals in health-compromising and risky ways (Ata et al. 2007). In fact, concern over such conceptual and methodological issues plagues a majority of the studies included in this review, as discussed below.

\section{Broad Conceptual and Methodological Challenges}

The findings of the current review revealed several conceptual and methodological issues that may have hampered the progress of research on gender and susceptibility to peer pressure. These concerns include a lack of careful consideration on the domain of risky behavior, gold standard measurement of peer pressure, and attention to the demographic characteristics of the sample.

\section{Domain of Risky Behavior}

First, the aforementioned issue of a lack of domain specificity is a challenge facing much of the research on gender differences in adolescent susceptibility to deviant peer pressure. In the present study, our operationalization of risktaking behaviors, while consistent with the literature, may overlook important areas in which clearer gender differences might emerge. For example, rather than describing males as more susceptible to peer pressure, it may be more accurate to describe females as less susceptible to deviant peer influences when risky behaviors are defined as delinquency and substance use, which were commonly assessed in the peer pressure measures included in this review. As such, it may be that more domain-general research (i.e., studies which include both more male-prone and female-prone risky behaviors) yields non-significant gender differences, whereas domain-specific studies reveal clearer and consistent gender differences. Similarly, whereas male proneness may exist more clearly when deviant peer pressure is measured using domain-specific, traditional risky behaviors (e.g., delinquency, misconduct), female proneness may be more apparent when studies specifically focus on other behavioral domains (e.g., those related to body image pressures).

Moreover, the issue of domain specificity may shed light on another finding in the present review: the small minority 
of studies ( $n=2$; Nahom et al. 2001; Shepherd et al. 2011) that demonstrated a greater female proneness to be susceptible to peer pressure. For example, Nahom et al. (2001) relied on a single, domain-specific item: peer pressure to have sexual intercourse. While unprotected sex during adolescence is more widely regarded an example of a risk-taking behavior, engaging in sexual intercourse in general does not necessarily convey risk. Given females' heightened sensitivity to social relationships (Rose and Rudolph 2006), it may be the case that females experience greater pressure than males to have sexual intercourse in order to meet relational goals (i.e., in order to preserve relationship harmony). It stands to reason that engagement in sexual intercourse, which is not necessarily a risky behavior, may be one specific domain where a female proneness to conform to peer pressure exists. However, De Gaston et al. (1996) also used a broad, singleitem measure with results indicating a contradictory finding, such that that males reported more pressure to have sexual intercourse. Thus, evidence for female sensitivity to deviant peer pressure in this review is weak and inconsistent.

\section{Measurement of Peer Pressure}

An issue related to the domain of risky behaviors concerns inconsistencies in the tools used to measure adolescent susceptibility to peer pressure. For example, most of the studies finding a male tendency to experience peer pressure used self-report measures focused on delinquency, misconduct and substance use (e.g., Berndt 1979; Bradley and Wildman 2002; Crockett et al. 2006; Duangpatra et al. 2009; Dumas et al. 2012). However, other studies showing this pattern of male-proneness used self-report measures that assessed broader experiences of peer pressure (Goldstein et al. 2005; Iwamoto and Smiler 2013; Steinberg and Monahan 2007; Sumter et al. 2009). Such inconsistencies in the tools used to assess susceptibility to deviant peer pressure complicate findings and make it challenging to determine whether there are reliable gender differences.

Moreover, while some authors used single-item scales (e.g. De Gaston et al. 2006; Nahom et al. 2001) or constructed their own scales (e.g., Maslowsky et al. 2011), other measures of peer pressure were more widely used. For example, the Peer Pressure Inventory (PPI; Brown et al. 1986a, b; Clasen and Brown 1985) assesses perceptions of explicit peer pressure across multiple domains and was used the most frequently in the literature. Other common assessment tools used included the Extreme Peer Orientation (Fuligni and Eccles 1993), the Emerging Adult Peer Pressure Inventory (EAPPI; Bradley and Wildman 2002), and the Resistance to Peer Influence scale (RPI; Steinberg and Monahan 2007). Such inconsistency in the tools used to measure adolescent susceptibility to peer pressure, in addition to the lack of attention to domain-specificity, likely contributes to the dearth of clear and consistent gender differences in adolescent susceptibility to peer influence. Even when gender was assessed in the studies included in this review, it was often not the primary focus of the research. Future research in this area would benefit from greater consistency and specificity in the risk domains assessed and in the tools used to assess them.

\section{Demographic Variables}

One limitation of the studies reviewed, and thus a limitation of the current study, is the lack of attention to demographic factors such as age and race which thereby prevented developmental or racial comparisons by gender. In regard to developmental status, several studies grouped early, middle and late adolescents together (Berndt 1979; Brown et al. 1986a, b; Clasen and Brown 1985; Crockett et al. 2006; Steinberg and Monahan 2007; Sumter et al. 2009), making it difficult for the present review to tease apart potential developmental differences in susceptibility to peer pressure between male and female adolescents. Future researchers are encouraged to report age differences in a more structured manner to determine whether susceptibility to deviant peer pressure follows a similar trajectory.

Similarly, a majority of studies did not report analyses of race separately for males and females. In addition, less than half of the studies included in the present review recruited samples that were racially and ethnically diverse (see Table 1). As such, the present study was unable to conduct a more fine-tuned analysis of racial or ethnic differences in susceptibility to peer pressure between males and females. Relatedly, while not included in the present review, cultural norms may influence adolescents' attitudes towards their peer groups and risky behavior. Given the aforementioned issues, future researchers are encouraged to focus on teasing apart the influences of age, race, culture, and domain of risky behavior on gender differences in adolescent susceptibility to deviant peer pressure.

\section{Conclusion}

There are both developmental and individual differences in the susceptibility to deviant peer pressure, which has been shown to be predictive of adolescent risk-taking behavior (Steinberg and Monahan 2007). Building on this understanding, the present review examined adolescents' susceptibility to peer pressure to engage in risky behaviors, and specifically, focused on how males and females may differ in their susceptibility to deviant peers. As such, the present study identified 26 studies that examined the association between gender and susceptibility to deviant peer pressure, and we introduced hypotheses to explain two 
primary trends: (1) adolescent males appear to be more susceptible to peer influences that encourage risk-taking behaviors, and (2) several studies indicated that there is no consistent gender difference. We offer two explanations based on our review of the literature: (1) gender role theory, which suggests that adolescent males experience more peer pressure for risk-taking; and (2) conceptual and methodological factors, which may obfuscate underlying patterns of gender differences in susceptibility based on contextual factors, or the outcome (i.e., type of risky behavior) under investigation. We observed both measurement inconsistencies and a lack of attention to contextual moderators, and encourage future psychologists, sociologists, and family researchers to empirically examine these hypotheses in order to determine appropriate targets of intervention. Empirical investigations of these hypotheses may reveal whether gender-specific programs that deal with decision-making in the context of peer relations would be effective in strengthening adolescents' ability to resist deviant peer influences.

Authors' contributions SSM conceived of the study, conducted the review searches and data abstraction, and drafted the manuscript. LMD participated in the conceptualization of the study, consolidated information from the collected literature, and created the table. DVS and MNN participated in the conceptualization of the study and contributed to the writing and critical revision of the manuscript. All authors read and approved the final manuscript.

\section{Compliance with ethical standards}

Conflict of interest The authors report no conflict of interests.

Open Access This article is distributed under the terms of the Creative Commons Attribution 4.0 International License (http://creativecommons.org/licenses/by/4.0/), which permits unrestricted use, distribution, and reproduction in any medium, provided you give appropriate credit to the original author(s) and the source, provide a link to the Creative Commons license, and indicate if changes were made.

\section{References}

Abbott-Chapman, J., Denholm, C., \& Wyld, C. (2007). Gender differences in adolescent risk taking: Are they diminishing? Youth and Society, 40(1), 131-154.

Allen, J. P., Chango, J., Szwedo, D., Schad, M., \& Marston, E. (2012). Predictors of susceptibility to peer influence regarding substance use in adolescence. Child Development, 83(1), 337-350. doi: 10.1111/j.1467-8624.2011.01682.x.

Allen, J. P., Porter, M. R., \& McFarland, F. C. (2006). Leaders and followers in adolescent close friendships: Susceptibility to peer influence as a predictor of risky behavior, friendship instability, and depression. Developmental Psychopathology, 18(1), 155-172.

Ata, R. N., Ludden, A. B., \& Lally, M. M. (2007). The effects of gender and family, friend, and media influences on eating behaviors and body image during adolescence. Journal of Youth and Adolescence, 36(8), 1024-1037. doi: 10.1007/s10964-006-9159-x.
Berndt, T. J. (1979). Developmental changes in conformity to peers and parents. Developmental Psychology, 15(6), 608-616. doi: 10.1037/0012-1649.15.6.608.

Blais, A.-R., \& Weber, E. U. (2001). Domain-specificity and gender differences in decision making. Risk Decision and Policy, 6(1), 47-69.

Blakemore, S.-J., \& Mills, K. L. (2014). Is adolescence a sensitive period for sociocultural processing? Annual Review of Psychology, 65, 187-207. doi: 10.1146/annurev-psych-010213-115202.

Bosson, J. K., Taylor, J. N., \& Prewitt-Freilino, J. L. (2006). Gender role violations and identity misclassification: The roles of audience and actor variables. Sex Roles, 55(1), 13-24. doi: 10.1007/ s11199-006-9056-5.

Boyer, T. W., \& Byrnes, J. P. (2009). Adolescent risk-taking: Integrating personal, cognitive, and social aspects of judgment. Journal of Applied Developmental Psychology, 30(1), 23-33. doi: 10.1016/j. appdev.2008.10.009.

Bradley, G., \& Wildman, K. (2002). Psychosocial predictors of emerging adults' risk and reckless behaviors. Journal of Youth and Adolescence, 31(4), 253-265. doi: 10.1023/A:1015441300026.

Brown, B. B. (1982). The extent and effects of peer pressure among high school students: A retrospective analysis. Journal of Youth and Adolescence, 11(2), 121-133. doi: 10.1007/BF01834708.

Brown, B. B., Classen, D. R., \& Eicher, S. A. (1986). Perceptions of peer pressure, peer conformity dispositions, and self-reported behavior among adolescents. Developmental Psychology, 22(4), 521-530.

Brown, B. B., Lohr, M. J., \& McClenahan, E. L. (1986). Early adolescents' perceptions of peer pressure. Journal of Early Adolescence, 6(2), 139-154. doi: 10.1177/0272431686062005.

Byrnes, J. P., Miller, D. C., \& Schafer, W. D. (1999). Gender differences in risk-taking: A meta-analysis. Psychological Bulletin, 125(3), 367-383. doi: 10.1037/0033-2909.125.3.367.

Cauffman, E., \& Steinberg, L. (2000). (Im)maturity of judgment in adolescence: Why adolescents may be less culpable than adults. Behavioral Sciences \& the Law, 18, 741-760.

Clasen, D. R., \& Brown, B. B. (1985). The multidimensionality of peer pressure in adolescence. Journal of Youth and Adolescence, 14(6), 451-468. doi: 10.1007/BF02139520.

Closson, L. M. (2009). Status and gender differences in early adolescents' descriptions of popularity. Social Development, 18(2), 412-426. doi: 10.1111/j.1467-9507.2008.00459.x.

Cohen, G. L., \& Prinstein, M. J. (2006). Peer contagion of aggression and health risk behavior among adolescent males: An experimental investigation of effects on public conduct and private attitudes. Child Development, 77(4), 967-983. doi: 10.1111/j.1467-8624.2006.00913.x.

Courtenay, W. H. (2000). Constructions of masculinity and their influence on men's well-being: a theory of gender and health. Social Science and Medicine, 50(10), 1385-1401. doi: 10.1016/ S0277-9536(99)00390-1.

Crockett, L. J., Raffaelli, M., \& Shen, Y.-L. (2006). Linking self-regulation and risk proneness to risky sexual behavior: Pathways through peer pressure and early substance use. Journal of Research on Adolescence, 16(4), 503-525. doi: 10.1111/j.1532-7795.2006.00505.x.

Crosnoe, R., \& McNeely, C. (2008). Peer relations, adolescent behavior, and public health research and practice. Family and Community Health, 31, 71-80. doi: 10.1097/01.FCH.0000304020.05632. e8.

De Gaston, J. F., Weed, S., \& Jensen, L. (1996). Understanding gender differences in adolescent sexuality. Adolescence, 31(121), $217-232$.

de Visser, O., \& McDonnell, E. J. (2011). 'That's OK. He's a guy': A mixed-methods study of gender double-standards for alcohol use. Psychology \& Health, 27, 618-639. 
Dishion, T. J., Spracklen, K. M., Andrews, D. W., \& Patterson, G. R. (1996). Deviancy training in male adolescent friendships. Behavior Therapy, 27(3), 373-390. doi: 10.1016/ S0005-7894(96)80023-2.

Duangpatra, K. N. K., Bradley, G. L., \& Glendon, A. I. (2009). Variables affecting emerging adults' self-reported risk and reckless behaviors. Journal of Applied Developmental Psychology, 30(3), 298-309. doi: 10.1016/j.appdev.2008.12.011.

Dumas, T. M., Ellis, W. E., \& Wolfe, D. A. (2012). Identity development as a buffer of adolescent risk behaviors in the context of peer group pressure and control. Journal of Adolescence, 35(4), 917-927. doi: 10.1016/j.adolescence.2011.12.012.

Erickson, K. G., Crosnoe, R., \& Dornbusch, S. M. (2000). A social process model of adolescent deviance: Combining social control and differential association perspectives. Journal of Youth and Adolescence, 29(4), 395-425. doi: 10.1023/A:1005163724952.

Fiske, S. T., \& Stevens, L. E. (1993). What's so special about sex? Gender stereotyping and discrimination. In S. Oskamp \& M. Costanzo (Eds.), Gender issues in contemporary society (pp. 173-196). Thousand Oaks: Sage Publications.

Flannery, D. J., Vazsonyi, A. T., Torquait, J., \& Fridrich (1994). Ethnic and gender differences in risky early adolescent substance use. Journal of Youth and Adolescence, 23(2), 195-213. doi: 10.1007/ BF01537445.

Freedman, B. J., Rosenthal, L., Donahoe, C. P. Jr., Schlundt, D. G., \& McFall, R. M. (1978). A social behavioral analysis of skill deficits in delinquent and nondelinquent adolescent boys. Journal of Consulting and Clinical Psychology, 46, 1448-1462.

Fuligni, A. J., \& Eccles, J. S. (1993). Perceived parent-child relationships and early adolescents' orientation toward peers. Developmental Psychology, 29(4), 622-632. doi: 10.1037/0012-1649.29.4.622.

Fuligni, A. J., Eccles, J. S., Barber, B. L., \& Clements, P. (2001). Early adolescent peer orientation and adjustment during high school. Developmental Psychology, 37(1), 28-36. doi: 10.1037/0012-1649.37.1.28.

Gaffney, L. R., \& McFall, R. M. (1981). A comparison of social skills in delinquent and nondeliqnuent adolescent girls using a behavioral role playing inventory. Journal of Consulting \& Clinical Psychology, 49, 959-967.

Galambos, N. L., Almeida, D. M., \& Petersen, A. C. (1990). Masculinity, femininity, and sex role attitude sin early adolescence: Exploring gender intensification. Child Development, 61(6), 1905-1914. doi: 10.1111/j.1467-8624.1990.tb03574.x.

Gardner, M., \& Steinberg, L. (2005). Peer influence on risk taking, risk preference, and risky decision making in adolescence and adulthood: An experimental study. Developmental Psychology, 41(4), 625-635. doi: 10.1037/0012-1649.41.4.625.

Gavin, L. A., \& Furman, W. (1989). Age differences in adolescents' perceptions of their peer groups. Developmental Psychology, 25(5), 827-834. doi:10.1037/0012-1649.25.5.827.

Gilligan, C. (1982). In a different voice: Psychological theory and women's development. Cambridge: Harvard University Press.

Goldstein, S. E., Davis-Kean, P. E., \& Eccles, J. S. (2005). Parents, peers, and problem behavior: A longitudinal investigation of the impact of relationship perceptions and characteristics on the development of adolescent problem behavior. Developmental Psychology, 41(2), 401-413.

Hanish, L. D., Martin, C. L., Fabes, R. A., Leonard, S., \& Herzog, M. (2005). Exposure to externalizing peers in early childhood: Homophily and peer contagion processes. Journal of Abnormal Child Psychology, 33(3), 267-281. doi: 10.1007/s10802-005-3564-6.

Heron, M. (2016). Deaths: Leading causes for 2013. National Vital Statistics Reports, 65(2). Hyattsville: National Center for Health Statistics.
Hill, J. P., \& Lynch, M. E. (1983). The intensification of genderrelated role expectations during early adolescence. In J. BrooksGunn et al. (Eds.), Girls at Puberty: Biological and Psychosocial Perspectives (pp. 201-228). New York: Springer. doi: 10.1007/978-1-4899-0354-9_10.

Iwamoto, D. K., \& Smiler, A. P. (2013). Alcohol makes you macho and helps you make friends: Role of masculine norms and peer pressure in adolescent boys' and girls' alcohol use. Substance Use and Misuse, 48(5), 371-378. doi:10.3109/10826084.2013.765479.

Keefe, K. (1994). Perceptions of normative social pressure and attitudes toward alcohol use: Changes during adolescence. Journal of Studies on Alcohol, 55, 46-54.

Knee, C. R., \& Neighbors, C. (2002). Self-determination, perception of peer pressure, and drinking among college students. Journal of Applied Social Psychology, 32(3), 522-543. doi:10.1111/j.1559-1816.2002.tb00228.x.

LaFontana, K. M., \& Cillessen, A. H. N. (2010). Developmental changes in the priority of perceived status in childhood and adolescence. Social Development, 19(1), 130-147. doi: 10.1111/j.1467-9507.2008.00522.x.

Leaper, C., \& Friedman, C. K. (2007). The socialization of gender. In J. E. Grusec \& P. D. Hastings (Eds.), Handbook of Socialization: Theory and Research (pp. 561-587). New York: Guilford Publications.

Mahalik, J. R., Burns, S. M., \& Syzdek, M. (2007). Masculinity and perceived normative health behaviors as predictors of men's health behaviors. Social Science and Medicine, 64(11), 2201-2209. doi: 10.1016/j.socscimed.2007.02.035.

Maslowsky, J., Keating, D., Monk, C., \& Schulenberg, J. (2011). Planned versus unplanned risks: Evidence for subtypes of risk behavior in adolescence. International Journal of Behavioral Development, 35(2), 152-160. doi:10.1177/0165025410378069.

Mears, D. P., Ploeger, M., \& Warr, M. (1998). Explaining the gender gap in delinquency: Peer influence and moral evaluations of behavior. Journal of Crime and Delinquency, 35(3), 251-266. doi: 10.1177/0022427898035003001.

Michael, K., \& Ben-Zur, H. (2007). Risk-taking among adolescents: associations with social and affective factors. Journal of Adolescence, 30(1), 17-31. doi: 10.1016/j.adolescence.2005.03.009.

Miller, H. V. (2009). If your friends jumped off a bridge, would you do it too? Delinquent peers and susceptibility to peer influence. Justice Quarterly, 27(4), 473-491. doi:10.1080/07418820903218974.

Moher, D., Liberati, A., Tetzlaff, J., Altman, D. G., \& The, PRISMA Group (2009). Preferred reporting items for systematic reviews and meta-analyses: The PRISMA Statement. PLoS Medicine 6(7):e1000097. doi:10.1371/journal.pmed.1000097.

Mora, R. (2012). "Do it all for your pubic hairs!": Latino boys, masculinity, and puberty. Gender and Society, 26(3), 433-460. doi: $10.1177 / 0891243212440502$.

Nahom, D., Wells, E., Gillmore, M. R., Hoppe, M., Morrison, D. M., Archibald, M., et al. (2001). Differences by gender and sexual experience in adolescent sexual behavior: Implications for education and HIV prevention. Journal of School Health, 71(4), $153-158$.

O’Brien, L., Albert, D., Chein, J., \& Steinberg, L. (2011). Adolescents prefer more immediate rewards when in the presence of their peers. Journal of Research on Adolescence, 21(4), 747-753. doi: 10.1111/j.1532-7795.2011.00738.x.

Perry, D. G., \& Pauletti, R. E. (2011). Gender and adolescent development. Journal of Research on Adolescence, 21(1), 61-74. doi: 10.1111/j.1532-7795.2010.00715.x.

Prinstein, M. J., Boergers, J., \& Spirito, A. (2001). Adolescents' and their friends' health-risk: behavior: Factors that alter or add to peer influence. Journal of Pediatric Psychology, 26(5), 287-298. doi: 10.1093/jpepsy/26.5.287. 
Prinstein, M. J., \& Wang, S. S. (2005). False consensus and adolescent peer contagion: Examining discrepancies between perceptions and actual reported levels of friends' deviant and health risk behaviors. Journal of Abnormal Child Psychology, 33(3), 293-306. doi: 10.1007/s10802-005-3566-4.

Rienzi, B. M., McMillin, J. D., Dickson, C. L., Crauthers, D., McNeill, K. F., Pesina, M. D., \& Mann, E. (1996). Gender differences regarding peer influence and attitude toward substance abuse. Journal of Drug Education, 26(4), 339-347. doi: 10.2190/52C7-5P6B-FPH2-K5AH.

Rose, A. J., \& Rudolph, K. D. (2006). A review of sex differences in peer relationship processes: Potential trade-offs for the emotional and behavioral development of girls and boys. Psychological Bulletin, 132(1), 98-131. doi: 10.1037/0033-2909.132.1.98.

Rudolph, K. D., \& Conley, C. S. (2005). The socioemotional costs and benefits of social-evaluative concerns: Do girls care too much? Journal of Personality, 73, 115-138. doi:10.1111/j.1467-6494.2004.00306.x.

Santor, D. A., Messervey, D., \& Kusumakar, V. (2000). Measuring peer pressure, popularity, and conformity in adolescent boys and girls: Predicting school performance, sexual attitudes, and substance abuse. Journal of Youth and Adolescence, 29(2), 163-182. doi: 10.1023/A:1005152515264.

Schulte, M. T., Ramo, D., \& Brown, S. A. (2009). Gender differences in factors influencing alcohol use and drinking progression among adolescents. Clinical Psychology Review, 29(6), 535-547. doi: 10.1016/j.cpr.2009.06.003.

Sheldon, A. (1992). Conflict talk: Sociolinguistic challenges to selfassertion and how young girls meet them. Merrill-Palmer Quarterly, 38, 95-117.

Shepherd, J. L., Lane, D. J., Tapscott, R. L., \& Gentile, D. A. (2011). Susceptible to social influence: Risky "driving" in response to peer pressure. Journal of Applied Social Psychology, 41(4), 773797. doi: 10.1111/j.1559-1816.2011.00735.x.

Sleet, D. A., Ballesteros, M. F., \& Borse, N. N. (2010). A review of unintentional injuries in adolescents. Annual Review of Public Health, 31, 195-212. doi: 10.1146/annurev. publhealth.012809.103616.

Steinberg, L., \& Monahan, K. C. (2007). Age differences in resistance to peer influence. Developmental Psychology, 43(6), 1531-1543. doi: 10.1037/0012-1649.43.6.1531.

Storvoll, E. E., \& Wichstrom, L. (2002). Do the risk factors associated with conduct problems in adolescents vary according to gender? Journal of Adolescence, 25(2), 183-202. doi: 10.1006/ jado.2002.0460.

Sumter, S. R., Bokhorst, C. L., Steinberg, L., \& Westenberg, P. M. (2009). The developmental pattern of resistance to peer influence in adolescence: Will the teenager ever be able to resist? Journal of Adolescence, 32(4), 1009-1021. doi: 10.1016/j. adolescence.2008.08.010.

Svensson, R. (2003). Gender differences in adolescent drug use: The impact of parental monitoring and peer deviance. Youth and Society, 34(3), 300-329. doi:10.1177/0044118X02250095.

Teese, R., \& Bradley, G. (2008). Predicting recklessness in emerging adults: A test of a psychosocial model. The Journal of Social Psychology, 148(1), 105-128. doi: 10.3200/SOCP.148.1.105-128.

Trucco, E. M., Colder, C. R., Bowker, J. C., \& Wieczorek, W. F. (2010). Interpersonal goals and susceptibility to peer influence: Risk factors for intentions to initiate substance use during early adolescence. The Journal of Early Adolescence, 31(4), 526-647. doi: $10.1177 / 0272431610366252$.

Turner, C., McClure, R., \& Pirozzo, S. (2004). Injury and risk-taking behavior-a systematic review. Accident Analysis and Prevention, 26(1), 93-101. doi: 10.1016/S0001-4575(02)00131-8.

Urberg, K. A. (1992). Locus of peer influence: Social crowd and best friend. Journal of Youth and Adolescence, 21(4), 439-450.

Young, A. M., Morales, M., McCabe, S. E., Boyd, C. J., \& D’Arcy, H. (2009). Drinking like a guy: Frequent binge drinking among undergraduate women. Substance Use and Misuse, 40(2), 241267. doi: 10.1081/JA-200048464. 